\title{
Pyroelectric Response of Lead Zirconate Titanate Thin Films on Silicon: Effect of Thermal Stresses
}

\author{
M. T. Kesim, ${ }^{1}$ J. Zhang, ${ }^{1}$ S. Trolier-McKinstry, ${ }^{2}$ J. V. Mantese, ${ }^{3}$ \\ R. W. Whatmore, ${ }^{4}$ and S. P. Alpay ${ }^{1}$ \\ ${ }^{1}$ Department of Materials Science and Engineering and Institute of Materials Science \\ University of Connecticut, Storrs, CT $06269-$ USA \\ ${ }^{2}$ Department of Materials Science and Engineering and Materials Research Institute, \\ Pennsylvania State University, PA 16802 - USA \\ ${ }^{3}$ United Technologies Research Center, East Hartford, CT 06118 - USA \\ ${ }^{4}$ Tyndall National Institute, Lee Maltings, Dyke Parade, \\ Cork City, County Cork - Ireland
}

\begin{abstract}
Ferroelectric lead zirconate titanate $\left[\mathrm{Pb}\left(\mathrm{Zr}_{x} \mathrm{Ti}_{1-x} \mathrm{O}\right)_{3}\right.$, (PZT $\left.\left.x: 1-x\right)\right]$ has received considerable interest for applications related to uncooled infrared devices due to its large pyroelectric figures of merit near room temperature and the fact that such devices are inherently ac coupled, allowing for simplified image post processing. For ferroelectric films made by industry-standard deposition techniques, stresses develop in the PZT layer upon cooling from the processing/growth temperature due to thermal mismatch between the film and the substrate. In this study, we use a non-linear thermodynamic model to investigate the pyroelectric properties of polycrystalline PZT thin films for five different compositions (PZT 40:60, PZT 30:70, PZT 20:80, PZT 10:90, PZT 0:100) on silicon as a function of processing temperature $\left(25-800^{\circ} \mathrm{C}\right)$. It is shown that the in-plane thermal stresses in PZT thin films alter the out-of-plane polarization and the ferroelectric phase transformation temperature, with profound effect on the pyroelectric properties. PZT 30:70 is found to have the largest pyroelectric coefficient $\left(0.042 \mu \mathrm{Ccm}^{-2 \circ} \mathrm{C}^{-1}\right.$, comparable to bulk values) at a growth temperature of $550^{\circ} \mathrm{C}$; typical to what is currently used
\end{abstract}


for many deposition processes. Our results indicate that it is possible to optimize the pyroelectric response of PZT thin films by adjusting the Ti composition and the processing temperature, thereby, enabling the tailoring of material properties for optimization relative to a specific deposition process. 


\section{INTRODUCTION}

Pyroelectric materials have long been employed as single or multi-element passive infrared devices for intrusion detectors, smoldering fire detectors, uncooled thermal imagers, radiometers, and gas/laser analyzers. ${ }^{1,2}$ These detectors are fabricated from either bulk or thin film elements. ${ }^{3}$ The pyroelectric response of such devices is commonly used in two different modes of operation. Firstly, for ferroelectric materials operated well below the ferroelectric (FE) phase transformation (Curie) temperature $\left(T_{C}\right)$ a pyroelectric current is obtained solely due to the change in spontaneous polarization with temperature. Intrusion detectors, gas analyzers are most often used in this mode. Such devices frequently are put into a "sleep mode" when inactive, and waking up upon external stimulus, thereby minimizing power consumption. ${ }^{4}$ Temperature variations and their control are not primary concerns in this mode of operation. Secondly, the socalled "dielectric bolometer" mode of operation involves using a ferroelectric material close to $T_{C}$, with an electric bias field applied, which has the effect of stabilizing a steep temperature dependence of the field induced dielectric displacement, and hence induced pyroelectric effect. ${ }^{5,6}$ The applied field also reduces the dielectric loss in the region of $T_{C}$, which would otherwise be problematic. The bolometer mode can be advantageous for certain types of device, especially small element thermal imaging arrays, where the high dielectric constant in the region of $T_{C}$ provides an element capacitance that matches the input amplifier. The need to operate close to $T_{C}$ necessitates some degree of temperature control, although the range of this is determined by the magnitude of the applied field (higher applied fields broaden the temperature range of optimum operation). Nevertheless, the need for thermal stabilization for dielectric bolometers is disadvantageous in terms of system complexity and power consumption and means that, for most IR sensing applications, the use of FEs well below $T_{C}$ provides a wider spectrum of applications. 
Ferroelectric materials, when deposited in thin film form, can exhibit inferior piezoelectric properties compared to bulk and single crystals due internal stresses, the presence of defects, and microstructural/compositional inhomogeneities. ${ }^{7-11}$ However, it has been shown that it is perfectly possible to obtain pyroelectric properties in ferroelectric thin films which compare very well with those of bulk pyroelectric ceramics ${ }^{12}$, presumably because such properties are intrinsic to the lattice and less dependent upon extrinsic effects such as domain wall motion than piezoelectricity. Such thin films offer significant advantages in terms of mass producibility, integration with other microelectronic devices, and lower processing costs. The lower heat capacity of thin films compared to their bulk counterparts improves the time response and sensitivity of the pyroelectric devices because a larger temperature rise is achieved for given infrared flux, thereby resulting in larger spontaneous voltage. Furthermore, it is possible to operate thin films (as dielectric bolometers) at high bias fields due to their relatively higher dielectric breakdown strengths and coercive fields. ${ }^{13-16}$

In order to integrate FE films into standard silicon-based integrated devices, the selected synthesis method through which the pyroelectric films are deposited should be compatible with conventional integrated circuitry (IC) as a post process, which means depositing the films below $500^{\circ} \mathrm{C} .{ }^{17,18}$ While there have been significant advances in industry-standard thin film growth techniques such as $r f$-sputtering, metal-organic chemical vapor deposition (MOCVD), and metalorganic solution deposition (MOSD); IC compatibility and cost considerations require that these films be deposited onto fully processed and metallized $\mathrm{Si}$ as end-of-line processes. This restriction may give rise to substantial material performance problems due to the relatively large thermal expansion coefficient (TEC) mismatch between a typical perovskite pyroelectric and Si. For example, in-plane thermal strains from the TEC difference may lead to cracking or 
delamination. In addition, excessively high post-processing temperatures for too long a period of time may degrade the aluminum metallization, or result in doping migration in the active silicon layers. The choice of temperature-time budget for the PZT annealing step in the fabrication of fully-integrated pyroelectric arrays thus requires some care, but it is feasible and fully working sol-gel fabricated integrated pyroelectric arrays have been demonstrated ${ }^{13}$.

The total polarization (spontaneous and induced) and its temperature dependence, defined through the pyroelectric coefficients, are intimately coupled with internal strains within the materials. ${ }^{14,19}$ As such, the electrical and mechanical boundary conditions are determined by the choice of a particular pyroelectric material, the substrate, the electrode configuration (top and bottom electrodes in a planar configuration or interdigitated electrodes), and processing conditions. There have been numerous theoretical and experimental studies that demonstrate the impact of residual strains which may result in deleterious effects on the FE thin film properties. ${ }^{7,820-24}$ Prior work also shows that the pyroelectric properties of FE thin films can be optimized through engineering misfit and thermal strains. ${ }^{14,19,25,26}$ For example, theoretical studies of barium strontium titanate $\left(\mathrm{Ba}_{x} \mathrm{Sr}_{1-x} \mathrm{TiO}_{3}, \mathrm{BST}\right)$ films on $\mathrm{Si}$ and sapphire substrates indicate that the pyroelectric response of these films may vary with film composition, the substrate material, and the processing temperature. ${ }^{6,14}$

Lead zirconate titanate $\left[\mathrm{Pb}\left(\mathrm{Zr}_{x} \operatorname{Ti}_{1-x} \mathrm{O}\right)_{3}\right.$, (PZT $\left.\left.x: 1-x\right)\right]$ thin films with $x \leq 0.5$ are of particular interest for IR devices due to their relatively large bulk pyroelectric properties at room temperature $\left(\mathrm{RT}=25^{\circ} \mathrm{C}\right) .{ }^{27,28}$ Indeed, it has been demonstrated that the pyroelectric properties of PZT films for Ti-rich compositions are strongly affected by the Ti composition, the domain structure, and residual strains. ${ }^{14,29}$ Secondary pyroelectric effects due to TEC mismatch can also be quite large for mono- and polydomain epitaxial PZT depending on the composition and may 
impact the overall pyroelectric response. ${ }^{29,30}$ The pyroelectric properties of PZT thin films can also be tailored through doping. In Table I, we summarize the typical room temperature pyroelectric coefficients of polycrystalline PZT thin films on Si or metallized Si substrates for Ti-rich compositions. ${ }^{31-45}$ Specific details corresponding to the Ti composition, synthesis method, processing temperatures, film thickness, and texture are provided in this summary. Table I shows that PZT 30:70 films that have a predominantly (111) texture yield the highest pyroelectric coefficients corresponding to $\sim 0.02 \mu \mathrm{Ccm}^{-2 \circ} \mathrm{C}^{-1} .12,13,46$

To understand: (i) why PZT 30:70 films have the strongest pyroelectric response, (ii) what the role of processing temperature (which determines the magnitude of the in-plane thermal strains) is, and (iii) how the pyroelectric coefficient of PZT films are related to film texture, we employ here a non-linear thermodynamic model based on Landau theory of phase transformations for FEs to account for the thermal strains in the thin film configuration. Our methodology provides quantitative predictions of the pyroelectric properties of (001)-textured polycrystalline PZT thin films on Si substrates as functions of film composition and processing temperature. The results suggest that the maximum pyroelectric response should be obtained for PZT 30:70 composition with a (001) texture, with tensile strains further enhancing the pyroelectric properties.

\section{THEORETICAL METHODOLOGY}

We consider here a (001)-textured, monodomain PZT film on a $\mathrm{Si}$ substrate deposited/processed at a growth/annealing temperature $T_{P}$ and then cooled to RT. While many thin films experimentally are polydomain, these calculations serve as a useful end member prediction. The excess free energy of such a system in the FE state can be expressed via: ${ }^{6}$ 


$$
\tilde{G}\left(P, T, u_{T}, E\right)=\tilde{\alpha}_{1} P^{2}+\tilde{\alpha}_{11} P^{4}+\alpha_{111} P^{6}+\frac{u_{T}^{2}}{S_{11}+S_{12}}-E P,
$$

where $P$ is the out-of-plane polarization, $E$ is the externally applied electric field and $u_{T}$ is the inplane thermal strain. This Landau expansion of the excess free energy of a uniaxial FE incorporates the internal elastic energy due to the mechanical boundary conditions in a thin film configuration given by $\sigma_{1}=\sigma_{2}$ and $\sigma_{3}=\sigma_{4}=\sigma_{5}=\sigma_{6}=0$, where $\sigma_{\mathrm{i}}$ are internal stresses in the contracted notation. The normalized dielectric stiffness coefficients in Eq. (1) are defined through:

$$
\begin{aligned}
& \tilde{1}_{1}{ }_{1} u_{T} \frac{2 Q_{12}}{S_{11}+S_{12}}, \\
& \tilde{\alpha}_{11}=\alpha_{11}+\frac{Q_{12}^{2}}{S_{11}+S_{12}},
\end{aligned}
$$

where $\alpha_{1}, \alpha_{11}$, and $\alpha_{111}$ are the dielectric stiffness coefficients. $\alpha_{1}$ is given by the Curie-Weiss Law such that, $\alpha_{1}=\left(T-T_{C}\right) / 2 \varepsilon_{0} C$, where $\varepsilon_{0}$ is the permittivity of vacuum and $C$ is the CurieWeiss constant. $Q_{12}$ is the electrostrictive coefficient, and $S_{11}$ and $S_{12}$ are the elastic compliances of the film at constant polarization. The thermodynamic, elastic and electromechanical data used in calculations can be found in Table II. ${ }^{47,48}$

Equi-biaxial in-plane thermal strains that develop in the film due to the differences in TECs between PZT $\left(\alpha_{P Z T}\right)$ and $\mathrm{Si}\left(\alpha_{S i}\right)$ upon cooling from $T_{P}$ can be expressed as:

$$
u_{T}\left(T_{G}\right)=\int_{R T}^{T_{P}} \alpha_{P Z T} d T-\int_{R T}^{T_{P}} \alpha_{S i} d T
$$

The TECs of pseudocubic PZT are taken to be dependent only on the film composition while $\alpha_{S i}$ changes as a function of temperature. ${ }^{49}$ The data for $\alpha_{P Z T}$ for PZT compositions 50:50, 30:70, and 0:100 $\left(\mathrm{PbTiO}_{3}, \mathrm{PT}\right)$ were obtained from the literature. 19,49-52 TECs for other compositions 
employed in our calculations were then calculated from a polynomial curve fitting such that:

$$
\alpha_{P Z T}(x)=\left(11.51-17.36 x+17.71 x^{2}\right) \times 10^{-6}{ }^{\circ} C^{-1},
$$

where $x$ is the mole fraction of Ti. Values for $\alpha_{P Z T}$ and $\alpha_{S i}$ that were used in our calculations are provided in Table III.

The condition for thermodynamic equilibrium is derived from the equation of state:

$$
\frac{\tilde{G}}{P}=2{ }_{1} P+4{ }_{11} P^{3}+6{ }_{111} P^{5}=E
$$

The spontaneous polarization $\left(P_{S}\right)$ of films can then be determined from $\tilde{G} / P=0(E=0)$ and the pyroelectric coefficient along [001] can be expressed as:

$$
p=\frac{d P_{S}}{d T}+\int_{0}^{E}\left(\frac{\partial \varepsilon}{\partial T}\right)_{E} d E
$$

The second term in Eq. (7) represents the contribution of the temperature dependence of the dielectric permittivity to the total pyroelectric coefficient and can be neglected around RT for the FE-PZT films considered in this study. As an example, for bulk PZT 20:80 at $200 \mathrm{kV} / \mathrm{cm}^{2}$; $d P_{S} / d T=0.031 \mu \mathrm{Ccm}^{-2 \circ} \mathrm{C}^{-1}$, whereas the $|p|$ defined through Eq. (7) including both terms is 0.033 $\mu \mathrm{Ccm}^{-2 \circ} \mathrm{C}^{-1}$.

\section{RESULTS AND DISCUSSION}

Figure 1(a) shows the temperature dependent out-of-plane polarization of polycrystalline bulk PZT. PZT 40:60 and 30:70 exhibit second order phase transitions as dictated by the positive signs of the quartic dielectric stiffness coefficients (Table III). Conversely, the order of the phase transition changes for high Ti compositions (PZT 20:80, PZT 10:90, PZT 0:100). It is also seen that increasing the Ti composition enhances the polarization and shifts the phase transition to higher temperatures, for the case of single domain state films. Strain-induced shifts in the phase 
transition temperature of FEs have been determined theoretically and experimentally. ${ }^{6,8,53,54}$ The polarizations of (001)-textured PZT films on Si as a function of temperature are plotted in Figure 1(b) at a $T_{P}$ of $550^{\circ} \mathrm{C}$. From Figure 1(b), the phase transitions of PZT films shift to lower temperatures compared to their bulk counterparts and become second order for all compositions due to modification of the quadratic dielectric stiffness coefficient as given through Eqs. (1) to (5). Such shifts have also been predicted via phase field models. ${ }^{55}$ The thermal strains are tensile in nature, since the TEC of PZT films are higher than Si for all compositions in the temperature range $\left(25-800^{\circ} \mathrm{C}\right)$ investigated in this study. Thermally-induced tensile strains couple with polarization and suppress it by counteracting to some extent the electrical dipole separation in the PZT films.

While the pyroelectric coefficient is the slope of the spontaneous polarization with temperature when operating significantly below the Curie temperature, a large absolute value of the polarization is also required to achieve good signal to noise in the readout IC of an infrared focal plane array (FPA). As seen from Table I, the processing temperature of PZT films on Si is reported to be roughly in the range between $500-750^{\circ} \mathrm{C}$. Therefore, the behavior of the polarization must be investigated over a wider temperature range in order to fully elucidate the effects of thermal strain. Figure 2 plots the [001] polarization of PZT films on Si as a function of $T_{P}$ in $25-800^{\circ} \mathrm{C}$ range. As expected, the spontaneous polarization is greater for lead titanate (PZT 0:100, PT) films compared to other PZT compositions. The TEC mismatch between the film and the substrate is more pronounced as the Ti composition is increased and reaches a maximum for PT films. Accordingly, the polarization drops more drastically for PT with increasing $T_{P}$ (i.e. the slope of $P$ vs. $T_{P}$ ) due to a build-up of a larger amount of tensile strain. On the other hand, polarization of PZT 40:60 films is found to be even more sensitive to $T_{P}$ although it has the 
lowest TEC among the films; a fact that can be attributed to the closer proximity of its $T_{C}$ to RT [Figure 1(b)]. Consequently, it is important to note that the polarization of PZT films depends on the complex interplay between $T_{P}$ and the film composition; both of which determine the magnitude of tensile strains and the phase transformation temperature.

The effects of thermal stresses on the RT pyroelectric properties of PZT thin films on Si as a function of $T_{P}$ are illustrated in Figure 3. The bulk values of PZT for the same compositions under zero bias fields are also indicated for comparison. Bulk single-domain PZT 40:60 has the highest pyroelectric coefficient $\left(0.042 \mu \mathrm{Ccm}^{-2 \circ} \mathrm{C}^{-1}\right)$; with an increase in $\mathrm{Ti}$ composition producing a deleterious effect on pyroelectric properties. On the other hand, for PZT thin films, there is also a composition (PZT 30:70) wherein a comparable pyroelectric response is observed. This latter composition is attractive in that it offers nearly a $20 \%$ larger spontaneous polarization compared to the 40:60 composition. Figure 3 also reveals that it is possible to improve upon the pyroelectric performance of bulk which has been reported for FE films and heterostructures in previous studies. ${ }^{6,56-58}$ The high pyroelectric response of the PZT 30:70 can be explained because the phase transformation temperature is sufficiently remote from RT to achieve a relatively large polarization, yet at the same time close enough to allow substantial polarization change with temperature. We note that experimentally PZT films on Si substrates contain polydomain microstructures that form so as to relax thermal stresses due to the TEC mismatch and the transformational stresses due to the FE-PE phase transformation at $T_{C}{ }^{59-66}$ Several studies have been reported which provide a rigorous analysis of polydomain heterostructures in epitaxial FEs taking into account these (volumetric) sources of internal stresses as well as localized strain fields near defects using thermodynamic models and phase-field approaches. ${ }^{20,55,67,68}$ Therefore, to describe the experimental observations, more sophisticated models need to be developed to 
describe the effect of grain and domain boundaries, grain texture, and the extrinsic contribution to the pyroelectric coefficient resulting from reversible domain wall motion.

The effect of a biasing electric field on pyroelectric coefficient of PZT films grown on Si at $550^{\circ} \mathrm{C}$ is demonstrated in Figure 4. An externally applied electrical field normal to the film/ substrate interface changes the free energy density as defined through Eq. (1). The applied electric field smears the phase transformation at $T_{C}$, thereby reducing the slope of the polarization vs. temperature curve and hence the pyroelectric response. A summary of our findings is illustrated in Figure 5 for PZT films on $\mathrm{Si}$ processed at 400,550 , and $700^{\circ} \mathrm{C}$ respectively. These temperatures were selected because they represent the typical minimum and typical maximum processing temperatures thus covering the whole processing temperature range reported in the literature (Table I). Regardless of the electric field strength $\left(50-200 \mathrm{kV} / \mathrm{cm}^{2}\right), \mathrm{PZT}$ 30:70 films have the highest $|p|$ with the pyroelectric properties of PZT films optimized by controlling both $T_{P}$ and the Ti composition.

The calculated RT pyroelectric coefficient for PZT 30:70 grown at $550^{\circ} \mathrm{C}$ under zero electrical field is approximately $0.04 \mu \mathrm{Ccm}^{-2 \circ} \mathrm{C}^{-1}$; almost two times larger than for PZT films of other composition processed around the same temperature. It should be emphasized that the result of the calculations presented herein is for the films which are assumed to be perfectly (001)-textured. In addition, many IR FPAs have partially released air bridge structures which partially diminish the effects of in-plane strains. Lastly, many films grown on platinized Si substrates with titanium adhesion layers adopt a highly textured (111) orientation. ${ }^{31}$ In other words, the polarization and pyroelectric vector components are along [111] and therefore, lower than the maximum allowable values obtained from [001]. ${ }^{24,28,31,32,46,69-71}$ In order to assess the contribution of [111]-aligned dipoles in our analysis, as a first-order approximation, the 
calculated polarization values and pyroelectric coefficients can be normalized by $1 / \sqrt{3}$ to account for geometrical considerations. ${ }^{32,72}$ This simple assumption decreases the computed pyroelectric coefficient to $\sim 0.02 \mu \mathrm{Ccm}^{-2 \circ} \mathrm{C}^{-1}$ in agreement with the experimental findings of (111)-textured films listed in Table I. However, to fully describe the polarization along [111] with biaxial inplane strain as defined in Sec. II, a more complicated thermodynamic analysis taking into account the anisotropic nature of the mechanical boundary conditions has to be employed. ${ }^{64,73}$ It is also obvious that it is necessary to find synthesis routes that will result in [001] oriented PZT films on Si to maximize the pyroelectric response.

\section{CONCLUSIONS}

In summary, we utilized a non-linear thermodynamic model to investigate the effect of thermally-induced strains on the pyroelectric properties of $\left[\mathrm{Pb}\left(\mathrm{Zr}_{x} \operatorname{Ti}_{1-x} \mathrm{O}\right)_{3}\right.$, $\left.(\mathrm{PZT} x: 1-x)\right]$ as a function of film composition (PZT 40:60, PZT 30:70, PZT 20:80, PZT 10:90, PZT 0:100) within a growth/processing temperature range of $25-800^{\circ} \mathrm{C}$ on IC-compatible $\mathrm{Si}$ substrates. We showed that the residual tensile strains in polycrystalline and monodomain PZT films enhance the pyroelectric response by altering the temperature dependent out-of-plane polarization and ferroelectric phase transition temperature. It is revealed that the pyroelectric properties of PZT films can be tailored by changing the processing temperature and the film composition both of which determine the magnitude of thermal strains. The results suggest that PZT 30:70 films offer a relatively large pyroelectric coefficient $\left(0.04 \mu \mathrm{Ccm}^{-2 \circ} \mathrm{C}^{-1}\right)$ at a typical deposition temperature of $550^{\circ} \mathrm{C}$. Finally, by considering the direction of the polarization vector and the degree of crystal orientation of PZT thin films, it is possible to predict the pyroelectric response. 


\section{ACKNOWLEDGEMENTS}

This publication was supported by the Pennsylvania State University Materials Research Institute Nanofabrication Lab and the National Science Foundation Cooperative Agreement No. ECS-0335765. 


\section{REFERENCES}

${ }^{1}$ R.W. Whatmore, Rep. Prog. Phys. 49, 1335 (1986).

${ }^{2}$ R.W. Whatmore, J. Electroceram. 13, 139 (2004).

${ }^{3}$ P. Muralt, Rep. Prog. Phys. 64, 1339 (2001).

${ }^{4}$ C.H. Tsai, Y.W. Bai, C.A. Chu, C.Y. Chung, and M.B. Lin, IEEE T. Consum. Electr. 57, (2011).

${ }^{5}$ R.W. Whatmore, Ferroelectrics 118, 241 (1991).

${ }^{6}$ J. Zhang, M.W. Cole, and S.P. Alpay, J. Appl. Phys. 108, 4103 (2010).

${ }^{7}$ S.P. Alpay, I.B. Misirlioglu, A. Sharma, and Z.G. Ban, J. Appl. Phys. 95, 8118 (2004).

${ }^{8}$ D.G. Schlom, L.Q. Chen, C.B. Eom, K.M. Rabe, K.S. Streiffer, and J.M. Triscone, Annu. Rev. Mater. Res. 37, 589 (2007).

${ }^{9}$ S. Trolier-McKinstry and P. Muralt, J. Electroceram. 12, 7 (2004).

${ }^{10}$ M.B. Okatan and S.P. Alpay, Appl. Phys. Lett. 95, 092902 (2009).

${ }^{11}$ I.B. Misirlioglu, S.P. Alpay, M. Aindow, and V. Nagarajan, Appl. Phys. Lett. 88, 102906 (2006).

${ }^{12}$ Q. Zhang and R.W. Whatmore, J. Appl. Phys. 94, 5228 (2003).

${ }^{13}$ N.M. Shorrocks, A. Patel, M.J. Walker, and A.D. Parsons, Microelectron. Eng. 29, 59 (1995).

${ }^{14}$ Z.G. Ban and S.P. Alpay, Appl. Phys. Lett. 82, 3499 (2003).

${ }^{15}$ M.A. Todd, P.A. Manning, P.P. Donohue, A.G. Brown, and R. Watton, in Proc. SPIE 4130, Infrared Technology and Applications XXVI, edited by B.F. Andersen, G.F. Fulop, and M.

Strojnik (San Diego, 2000), pp. 128-139.

${ }^{16}$ M.H. Lee, R. Guo, and A.S. Bhalla, J. Electroceram. 2, 229 (1998).

${ }^{17}$ N. Setter and R. Waser, Acta Mater. 48, 151 (2000).

${ }^{18}$ R.W. Whatmore, P. Kirby, A. Patel, N.M. Shorrocks, T. Bland, and M. Walker, Science and Technology of Electroceramic Thin Films (Kluwer Academic Publishers, 1995), pp. 383-397.

${ }^{19}$ A. Sharma, Z.G. Ban, S.P. Alpay, and J. V. Mantese, J. Appl. Phys. 95, 3618 (2004). 
${ }^{20}$ P.E. Janolin, J. Mater. Sci. 44, 5025 (2009).

${ }^{21}$ M.B. Kelman, P.C. McIntyre, B.C. Hendrix, S.M. Bilodeau, and J.F. Roeder, J. Appl. Phys. 93, 9231 (2003).

${ }^{22}$ M. Dawber, K.M. Rabe, and J.F. Scott, Rev. Mod. Phys. 77, 1083 (2005).

${ }^{23}$ N. Setter, D. Damjanovic, L. Eng, G. Fox, S. Gevorgian, S. Hong, A. Kingon, H. Kohlstedt, N.Y. Park, G.B. Stephenson, I. Stolitchnov, A.K. Taganstev, D. V. Taylor, T. Yamada, and S. Streiffer, J. Appl. Phys. 100, 051606 (2006).

${ }^{24}$ R.J. Ong, D.A. Payne, and N.R. Sottos, J. Am. Ceram. Soc. 88, 2839 (2005).

${ }^{25}$ H.X. Cao, V.C. Lo, and Z.Y. Li, J. Appl. Phys. 101, 014113 (2007).

${ }^{26}$ Y. Zheng, B. Wang, and C.H. Woo, Appl. Phys. Lett. 89, 062904 (2006).

${ }^{27}$ P. Muralt, J. Micromech. Microeng. 10, 136 (2000).

${ }^{28}$ R. Bruchhaus, D. Pitzer, R. Primig, M. Schreiter, W. Wersing, N. Neumann, N. Hess, J. Vollheim, R. Kohler, and M. Simon, Integr. Ferroelectr. 17, 37 (1997).

${ }^{29}$ J. Karthik and L.W. Martin, Phys. Rev. B 84, 4102 (2011).

${ }^{30}$ J. Karthik, J.C. Agar, A.R. Damodaran, and L.W. Martin, Phys. Rev. Lett. 109, 7602 (2012).

${ }^{31}$ N.M. Shorrocks, A. Patel, and A.D. Parsons, Microelectron. Eng. 29, 59 (1995).

${ }^{32}$ M. Kohli, A. Seifert, and P. Muralt, Integr. Ferroelectr. 22, 37 (1998).

${ }^{33}$ R. Kohler, G. Suchaneck, P. Padmini, T. Sandner, G. Gerlach, and G. Hofmann, Ferroelectrics 225, 57 (1998).

${ }^{34}$ R. Kohler, P. Padmini, G. Gerlach, G. Hofmann, and R. Bruchhaus, Integr. Ferroelectr. 22, 383 (1998).

${ }^{35}$ Q. Zhang and R.W. Whatmore, J. Phys. D: Appl. Phys. 34, 2296 (2001).

${ }^{36}$ Q. Tan, W. Zhang, C. Xue, J. Xiong, J. Liu, J. Li, and T. Liang, Microelectron. J. 40, 58 (2009).

${ }^{37}$ W. Liu, J.S. Ko, and W. Zhu, Thin Solid Films 371, 254 (2000).

${ }^{38}$ Y. Guo, D. Akai, K. Swada, and M. Ishida, Appl. Phys. Lett. 90, 232908 (2007).

${ }^{39}$ J.S. Ko, W. Liu, W. Zhu, and B.M. Kwak, Solid State Electron. 46, 1155 (2002). 
${ }^{40}$ Z. Huang, Q. Zhang, and R.W. Whatmore, J. Appl. Phys. 85, 7355 (1999).

${ }^{41}$ L.L. Sun, O.K. Tan, and W.G. Zhu, J. Appl. Phys. 99, 094108 (2006).

${ }^{42}$ S. Corkovic and Q. Zhang, J. Appl. Phys. 105, 061610 (2009).

${ }^{43}$ L.L. Sun, W.G. Liu, O.K. Tan, and W. Zhu, Mater. Sci. Eng. B 99, 173 (2003).

${ }^{44}$ S.H. Kang, H.J. Lee, J.L. Kim, I.W. Kim, E.C. Park, J.S. Lee, and S.S. Yi, Ferroelectrics 328, 47 (2005).

${ }^{45}$ G. Gerlach, G. Suchaneck, R. Kohler, T. Sandner, P. Padmini, R. Krawietz, W. Pompe, J. Frey, O. Jost, and A. Schonecker, Ferroelectrics 230, 109 (1999).

${ }^{46}$ Z. Huang, Q. Zhang, and R.W. Whatmore, J. Appl. Phys. 85, 7355 (1999).

${ }^{47}$ M.J. Haun, Z.Q. Zhuang, E. Furman, S.J. Jang, and L.E. Cross, Ferroelectrics 99, 37 (1989).

${ }^{48}$ N. Pertsev, V. Kukhar, H. Kohlstedt, and R. Waser, Phys. Rev. B 67, 054107 (2003).

${ }^{49}$ Y. Okada and Y. Tokumaru, J. Appl. Phys. 56, 314 (1984).

${ }^{50}$ M.J. Haun, E. Furman, H.A. McKinstry, and L.E. Cross, Ferroelectrics 99, 27 (1989).

${ }^{51}$ T. Ohno, H. Suzuki, D. Fu, M. Takahashi, T. Ota, and K. Ishikawa, Ceram. Int. 30, 1487 (2004).

${ }^{52}$ R.S. Batzer, B.M. Yen, D. Liu, H. Chen, H. Kubo, and G.R. Bai, J. Appl. Phys. 80, 6235 (1996).

${ }^{53}$ D.A. Tenne, A. Soukiassian, X.X. Xi, T.R. Taylor, P.J. Hansen, J.S. Speck, and R.A. York, Appl. Phys. Lett. 85, 4124 (2004).

${ }^{54}$ H.X. Cao, V.C. Lo, and W.W.Y. Chung, J. Appl. Phys. 99, 024103 (2006).

${ }^{55}$ L.Q. Chen, J. Am. Ceram. Soc. 91, 1835 (2008).

${ }^{56}$ F. Jin, G.W. Auner, R. Naik, N.W. Schubring, J. V. Mantese, A.B. Catalan, and A.L. Micheli, Appl. Phys. Lett. 73, 2838 (1998).

${ }^{57}$ N.W. Schubring, J. V Mantese, A.L. Micheli, A.B. Catalan, and R.J. Lopez, Phys. Rev. Lett. 68, 1778 (1992).

${ }^{58}$ Y. Ivry, V. Lyahovitskaya, I. Zon, I. Lubomirsky, E. Wachtel, and A.L. Roytburd, Appl. Phys. Lett. 90, 172905 (2007). 
${ }^{59}$ G.L. Brennecka, W. Huebner, B.A. Tuttle, and P.G. Clem, J. Am. Ceram. Soc. 87, 1459 (2004).

${ }^{60}$ S. Utsugi, T. Fujisawa, Y. Ehara, T. Yamada, M. Matsushima, H. Morioka, and H. Funakubo, Appl. Phys. Lett. 96, 102905 (2010).

${ }^{61}$ S. Trolier-Mckinstry, J.F. Shepard Jr, J.L. Lacey, T. Su, G. Zavala, and J. Fendler, Ferroelectrics 206, 381 (1998).

62 J.F. Shepard, S. Trolier-McKinstry, M. Hendrickson, and R. Zeto, in Materials for Smart Systems II: Vol. 459 Materials Research Society Symposium Proceedings, edited by E.P. George, R. Gotthardt, K. Otsuka, S. Trolier-McKinstry, and M. WunFogle (Materials Research Society, Boston, 1997), pp. 47-51.

${ }^{63}$ Q.Y. Qiu, S.P. Alpay, and V. Nagarajan, J. Appl. Phys. 107, 114105 (2010).

${ }^{64}$ G. Akcay, I.B. Misirlioglu, and S.P. Alpay, J. Appl. Phys. 101, 104110 (2007).

${ }^{65}$ Q. Qiu, V. Nagarajan, and S. Alpay, Phys. Rev. B 78, 064117 (2008).

${ }^{66}$ H. Funakubo, M. Dekkers, A. Sambri, S. Gariglio, I. Shklyarevskiy, and G. Rijnders, MRS Bulletin 37, 1030 (2012).

${ }^{67}$ N.A. Pertsev and V.G. Koukhar, Phys. Rev. B 84, 3722 (2000).

${ }^{68}$ S.P. Alpay and A.L. Roytburd, J. Appl. Phys. 83, 4714 (1998).

${ }^{69}$ J. Ricote, D. Chateigner, L. Pardo, M. Alguero, J. Mendiola, and M.L. Calzada, Ferroelectrics 241, 167 (2000).

${ }^{70}$ P. Muralt, IEEE T. Ultrason. Ferr. 47, 903 (2000).

${ }^{71}$ D. Ambika, V. Kumar, K. Tomioka, and I. Kanno, Adv. Mat. Lett. 3, 102 (2012).

${ }^{72}$ Q. Du, J. Li, W. Nothwang, and M.W. Cole, Acta Mater. 54, 2577 (2006).

73 A.G. Zembilgotov, N.A. Pertsev, U. Böttger, and R. Waser, Appl. Phys. Lett. 86, 052903 (2005). 


\section{FIGURE CAPTIONS}

Figure 1: (Color online) Temperature dependent polarization of (a) bulk, polycrystalline PZT and (b) (001)-textured PZT on $\mathrm{Si}\left(T_{P}=550^{\circ} \mathrm{C}\right)$ at various compositions.

Figure 2: (Color online) [001] polarization of PZT thin films with different Ti composition as a function of the growth temperature.

Figure 3: (Color online) Pyroelectric coefficients of PZT thin films on $\mathrm{Si}$ for five compositions as a function of the growth temperature. The arrows indicate pyroelectric coefficients of bulk PZT under zero bias field.

Figure 4: (Color online) Pyroelectric coefficients of (001)-textured polycrystalline PZT films $\left(T_{P}=550^{\circ} \mathrm{C}\right)$ for five compositions as a function of the applied bias field.

Figure 5: (Color online) Pyroelectric coefficient of PZT thin films on Si grown/processed at (a) $400^{\circ} \mathrm{C}$, (b) $550^{\circ} \mathrm{C}$ and (c) $700^{\circ} \mathrm{C}$ as functions of $\mathrm{Ti}$ composition and the applied electric fields. 
Table I. Summary of pyroelectric properties of typical polycrystalline PZT thin films on Si substrates (Ti-rich compositions). Also included in the list are the deposition method, deposition parameters, texture, and film thickness.

\begin{tabular}{|c|c|c|c|c|c|c|c|}
\hline $\begin{array}{l}\text { Composition } \\
\text { (Zr:Ti) }\end{array}$ & $\begin{array}{c}\text { Orientation/ } \\
\text { Texture }\end{array}$ & Substrate & Method & $\begin{array}{c}\text { Processing } \\
\text { Temperature } \\
\left({ }^{\circ} \mathbf{C}\right)\end{array}$ & $\begin{array}{c}\text { Pyroelectric } \\
\text { coefficient } \\
\left(\mu \mathrm{Ccm}^{-2 \circ} \mathrm{C}^{-1}\right)\end{array}$ & $\begin{array}{l}\text { Thickness } \\
\text { (nm) }\end{array}$ & References \\
\hline $30: 70$ & \multirow{4}{*}{ Highly (111) } & \multirow{4}{*}{$\mathrm{Si} / \mathrm{Ti} / \mathrm{Pt}$} & \multirow{4}{*}{ Sol-gel } & 510 & 0.03 & \multirow{4}{*}{1000} & \multirow{4}{*}{31} \\
\hline $30: 70$ & & & & $\approx 500-510$ & $0.02-0.029$ & & \\
\hline $25: 75$ & & & & 510 & 0.022 & & \\
\hline $20: 80$ & & & & 510 & 0.018 & & \\
\hline \multirow{2}{*}{$15: 85$} & $(111)-80 \%$ & \multirow{2}{*}{$\mathrm{Si} / \mathrm{TiO}_{2} / \mathrm{Pt}$} & \multirow{2}{*}{ Sol-gel } & \multirow{2}{*}{$580-650$} & 0.022 & \multirow{2}{*}{1000} & \multirow{2}{*}{32} \\
\hline & $(100)-48 \%$ & & & & 0.0186 & & \\
\hline $25: 75$ & $(111)$ & $\mathrm{Si} / \mathrm{TiO}_{2} / \mathrm{Pt}$ & Sputtering & 450 & 0.02 & $400-1000$ & 33,34 \\
\hline $30: 70$ & Highly (111) & $\mathrm{Si} / \mathrm{Ti} / \mathrm{Pt}$ & Sol-gel & 530 & 0.0211 & 700 & 35 \\
\hline $30: 70$ & Random & $\mathrm{Si} / \mathrm{Ti} / \mathrm{Pt}$ & Sol-gel & 650 & $0.00112 @ 50^{\circ} \mathrm{C}$ & 500 & 36 \\
\hline $30: 70$ & Random & $\mathrm{Si} / \mathrm{Ti} / \mathrm{Pt}$ & Sol-gel & 600 & 0.04 & 550 & 37 \\
\hline $40: 60$ & $(110)-93 \%$ & $\mathrm{Si} / \mathrm{LNO} / \mathrm{Pt}$ & Sputtering & 650 & $\begin{array}{l}0.078 \text { (avg.) } \\
0.109 \text { (max.) }\end{array}$ & 500 & 38 \\
\hline $30: 70$ & Random & $\mathrm{Si} / \mathrm{Ti} / \mathrm{Pt}$ & Sol-gel & 600 & 0.025 & 550 & 39 \\
\hline $30: 70$ & Highly (111) & $\mathrm{Si} / \mathrm{Ti} / \mathrm{Pt}$ & Sol-gel & 480 & 0.018 & 800 & 40 \\
\hline $30: 70$ & Random & $\mathrm{Si} / \mathrm{Ti} / \mathrm{Pt}$ & Sol-gel & 640 & 0.029 & 450 & 41 \\
\hline $30: 70$ & $(100) /(111)$ & $\mathrm{Si} / \mathrm{Ti} / \mathrm{Pt}$ & Sol-gel & 530 or 560 & 0.032 & 1000 & 42 \\
\hline $30: 70$ & Random & $\mathrm{Si} / \mathrm{Ti} / \mathrm{Pt}$ & Sol-gel & $560-700$ & $0.010-0.017$ & 450 & 43 \\
\hline $30: 70$ & N/A & $\mathrm{Si} / \mathrm{Ti} / \mathrm{Pt}$ & Sol-gel & 650 & $0.018 @ 260^{\circ} \mathrm{C}$ & N/A & 44 \\
\hline \multirow{2}{*}{$25: 75$} & $(100) /(111)$ & \multirow{2}{*}{$\mathrm{Si} / \mathrm{Ti} / \mathrm{Pt}$} & Sol-gel & 750 & 0.021 & \multirow{2}{*}{ N/A } & \multirow[t]{2}{*}{45} \\
\hline & $(111)$ & & Sputtering & 600 & 0.020 & & \\
\hline
\end{tabular}


Table II. Bulk thermodynamic, elastic, and electromechanical coefficients of PZT.

\begin{tabular}{|c|c|c|c|c|c|}
\hline & $\begin{array}{c}\text { PZT } \\
40 / 60\end{array}$ & $\begin{array}{c}\text { PZT } \\
30 / 70\end{array}$ & $\begin{array}{c}\text { PZT } \\
20 / 80\end{array}$ & $\begin{array}{c}\text { PZT } \\
10 / 90\end{array}$ & $\begin{array}{c}\text { PZT } \\
0 / 100 \\
(\mathrm{PT}) \\
\end{array}$ \\
\hline$T_{C}\left({ }^{\circ} C\right)$ & 418.4 & 440.2 & 459.1 & 477.1 & 492.1 \\
\hline$C\left(10^{5} \mathrm{C}\right)$ & 2.664 & 1.881 & 1.642 & 1.547 & 1.500 \\
\hline$Q_{11}\left(\mathrm{~m}^{4} / \mathrm{C}^{2}\right)$ & 0.08116 & 0.07887 & 0.08142 & 0.08504 & 0.08900 \\
\hline$Q_{12}\left(\mathrm{~m}^{4} / \mathrm{C}^{2}\right)$ & -0.0295 & -0.0248 & -0.02446 & -0.02507 & -0.02600 \\
\hline$s_{11}\left(10^{-12} \mathrm{~N} / \mathrm{m}^{2}\right)$ & 8.6 & 8.4 & 8.2 & 8.1 & 8 \\
\hline$s_{12}\left(10^{-12} \mathrm{~N} / \mathrm{m}^{2}\right)$ & -2.8 & -2.7 & -2.6 & -2.5 & -2.5 \\
\hline$\alpha_{11}\left(10^{7} \mathrm{~N} \mathrm{~m}^{6} / \mathrm{C}^{4}\right)$ & 3.614 & 0.6458 & -3.05 & -5.845 & -7.253 \\
\hline$\alpha_{111}\left(10^{8} \mathrm{~N} \mathrm{~m}^{10} / \mathrm{C}^{6}\right)$ & 1.859 & 2.348 & 2.475 & 2.518 & 2.606 \\
\hline
\end{tabular}

Table III. TEC of PZT films as a function of composition and TEC of Si.

\begin{tabular}{ccc}
\hline Film/Substrate & TEC, $\times \mathbf{1 0}^{\mathbf{6}}\left({ }^{\circ} \mathrm{C}^{-1}, \mathrm{~T}\right.$ in $\left.{ }^{\circ} \mathrm{C}\right)$ & Ref. \\
\hline PZT 50:50 & 7.26 & 19 \\
PZT 40:60 & 7.47 & - \\
PZT 30:70 & 8.04 & 50 \\
PZT 20:80 & 8.96 & - \\
PZT 10:90 & 10.23 & - \\
PZT 0:100 & 11.86 & 51,52 \\
Si & $3.725 \times\left\{1-\exp \left[-5.88 \times 10^{-3}(T+149)\right]\right\}+5.548 \times$ & 49 \\
& $10^{-4} \times(T+273)$ & \\
\hline \hline
\end{tabular}


Figure 1
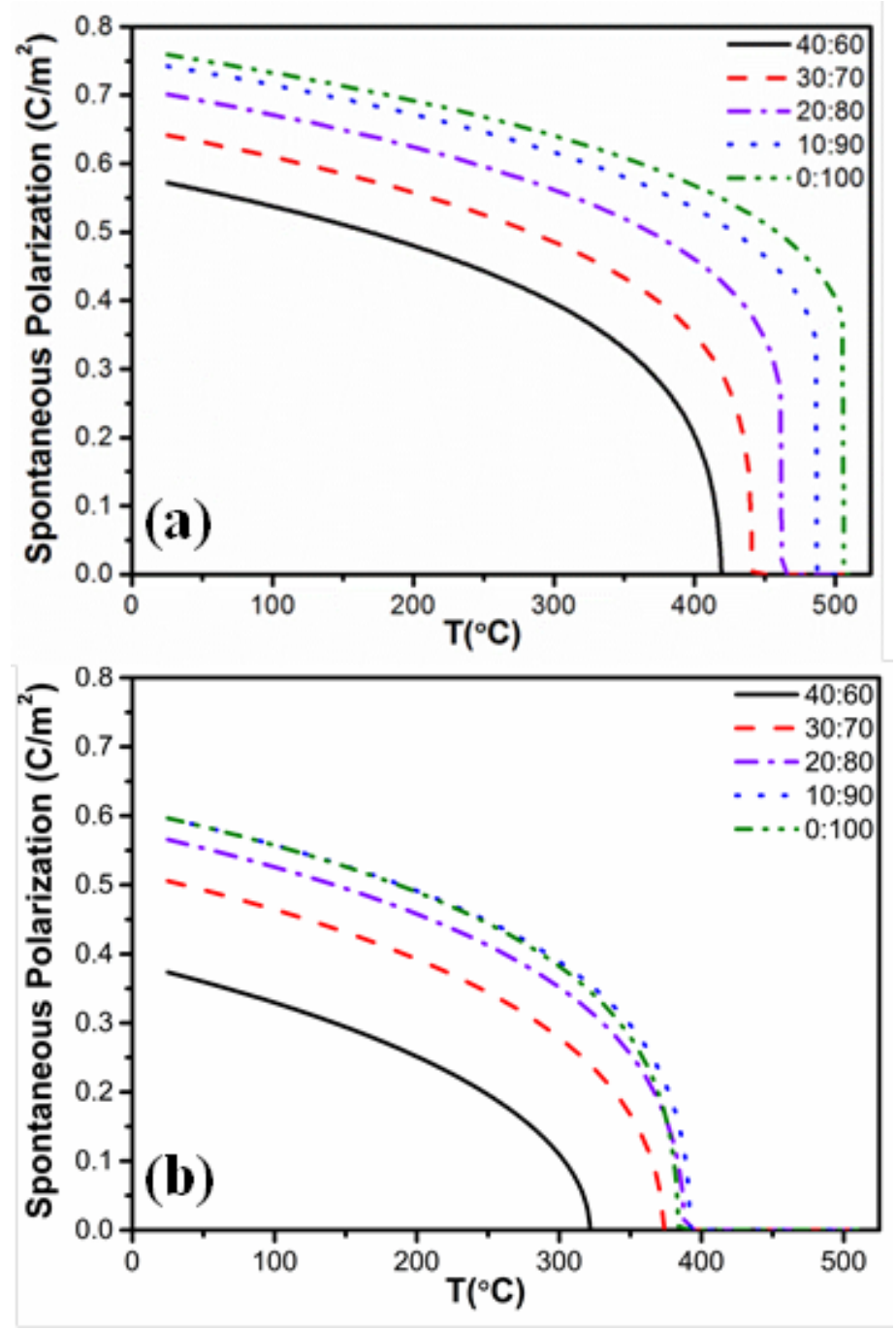
Figure 2

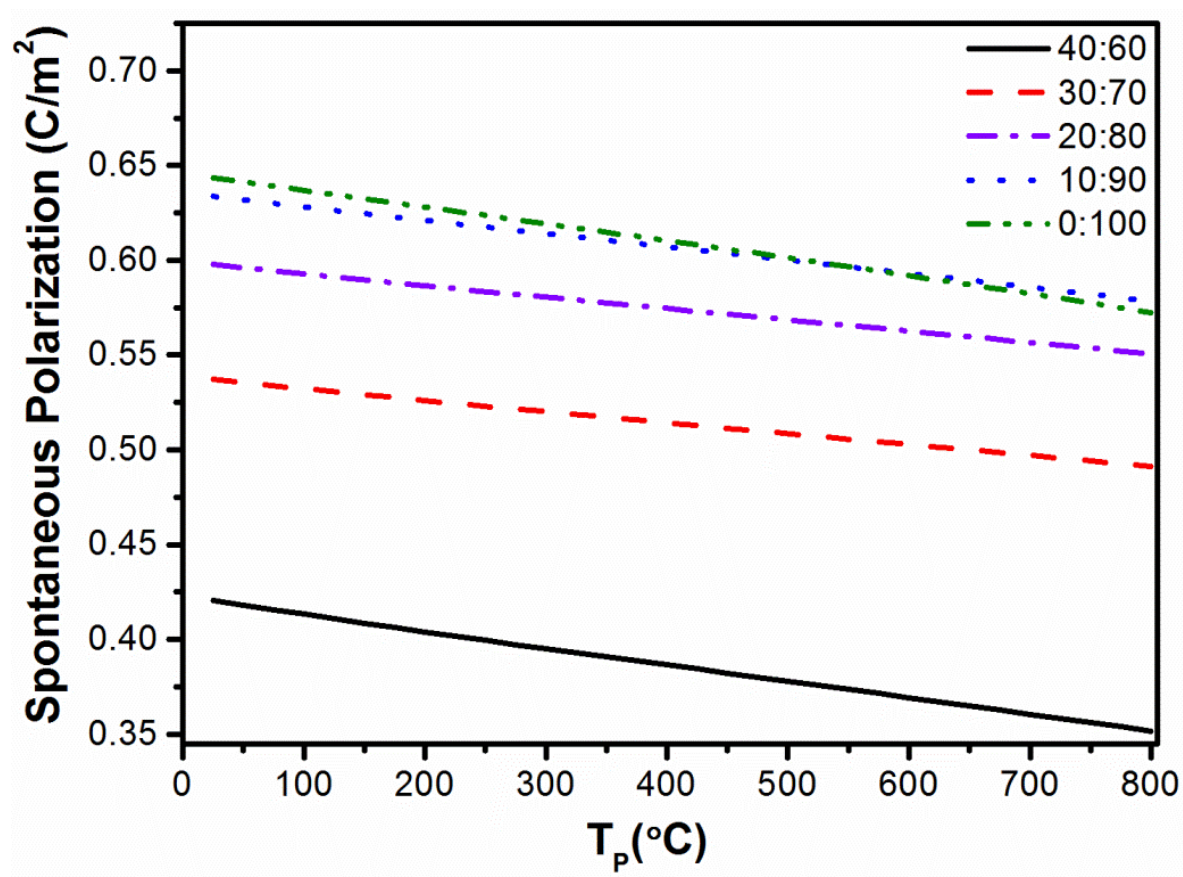


Figure 3

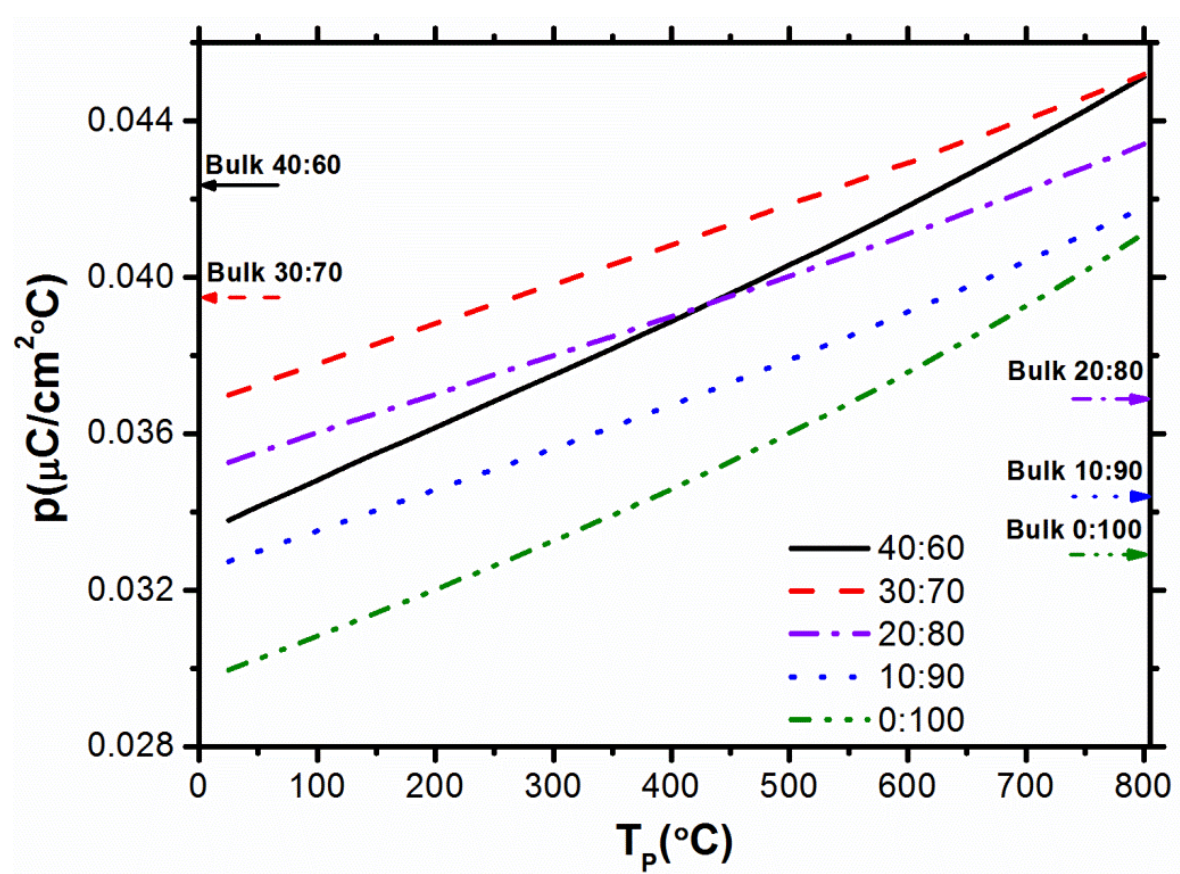


Figure 4

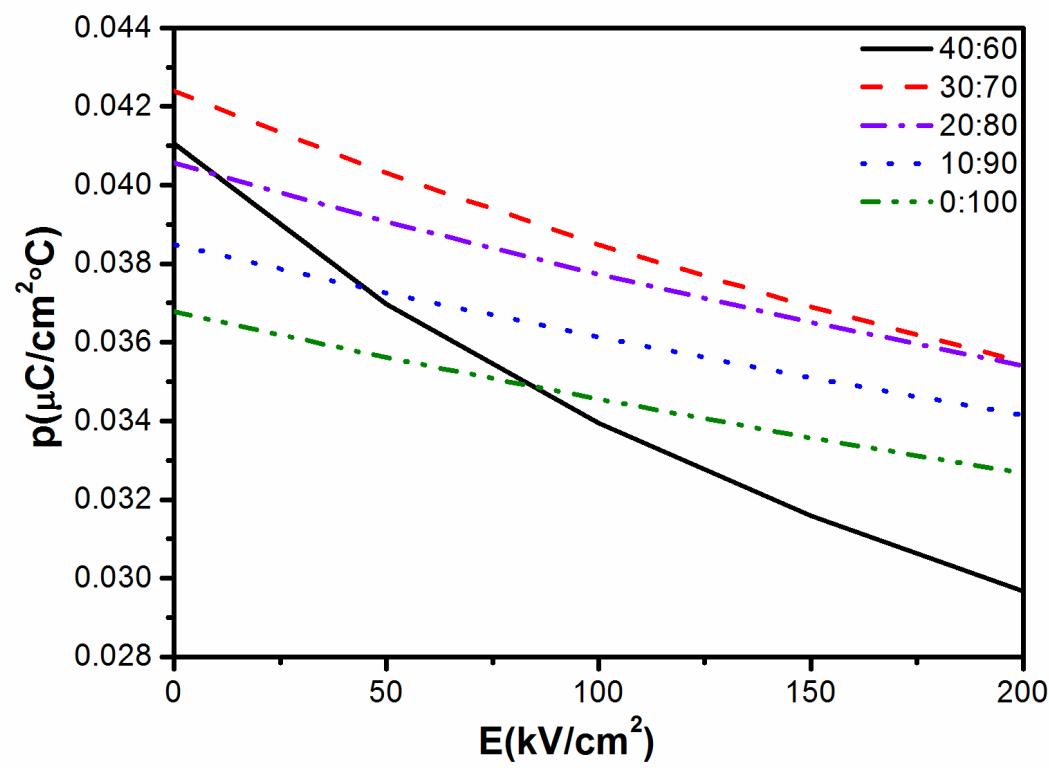




\section{Figure 5}
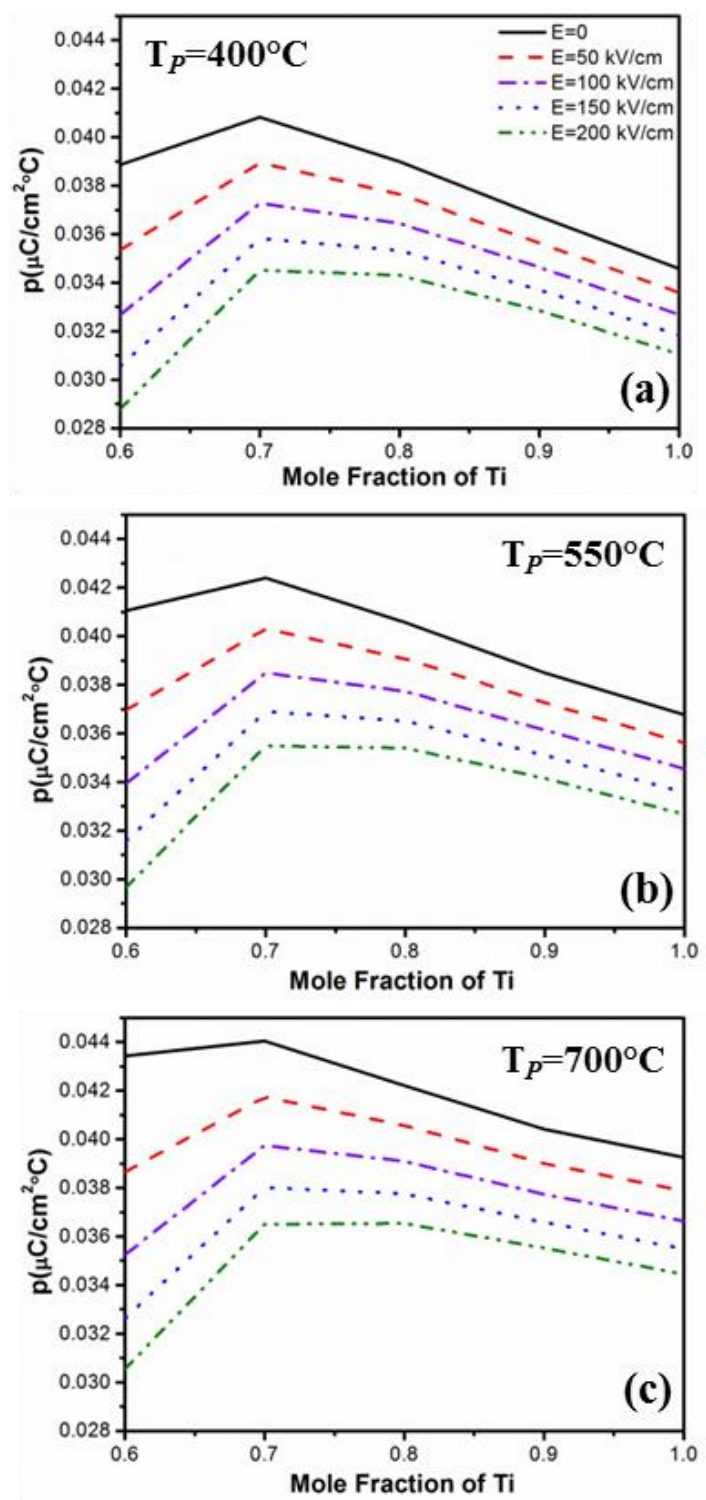